\title{
Improving Nuclear Power Plant Safety with FeCrAl Alloy Fuel Cladding
}

\author{
Raul B. Rebak, ${ }^{1}$ Kurt A. Terrani, ${ }^{2}$ William P. Gassmann, ${ }^{3}$ John B. Williams, ${ }^{4}$ Kevin L. Ledford ${ }^{5}$ \\ ${ }^{1}$ GE Global Research, 1 Research Circle, CEB2551, Schenectady, NY 12309, U.S.A. \\ ${ }^{2}$ Oak Ridge National Laboratory, Oak Ridge, TN 37831 \\ ${ }^{3}$ Exelon Generation, Kennett Square, PA 19348 \\ ${ }^{4}$ Southern Nuclear, Chelsea, AL 35043 \\ ${ }^{5}$ Global Nuclear Fuels Americas, Wilmington NC 28401
}

\begin{abstract}
The US Department of Energy (DOE) is partnering with fuel vendors to develop enhanced accident tolerant nuclear fuels for Generation III water cooled reactors. In comparison with the standard current uranium dioxide and zirconium alloy system UO2-Zr), the proposed alternative accident tolerant fuel (ATF) should better tolerate loss of cooling in the core for a considerably longer time while maintaining or improving the fuel performance during normal operation conditions. General Electric, Oak Ridge National Laboratory and their partners have proposed to replace zirconium based alloy cladding in current commercial power reactors with an iron-chromium-aluminum ( $\mathrm{FeCrAl}$ ) alloy cladding such as APMT. The use of FeCrAl alloys will greatly reduce the risk of operating the power reactors to produce electricity.
\end{abstract}

\section{INTRODUCTION}

Nuclear power plants are one of the most reliable and cleaner ways of producing electricity. For the last 60 years, commercial nuclear power plants have been used in $30+$ countries to produce low cost electricity [1]. Commercial nuclear power plants (NPP) are designed to be operated without significant effect on the public health and safety and effect on the environment [2]. The main risk of operating a nuclear power plant is the release of radioactive elements into the environment, and for that reason, several barriers are constructed between the fuel containing the radioactive elements and the environment. The first barrier to protect the fuel is the hermetically sealed metallic cladding which envelops the pellets of uranium oxide. That is, maintaining the integrity of the cladding is the first crucial containment for the radioactive material. Further barriers include the reactor pressure vessel, the concrete building structure containing the pressure vessel and abundant amounts of water that remove the heat from the nuclear reaction [2].

The Nuclear Regulatory Commission (NRC) uses probabilistic risk assessment (PRA) methods to assess the likelihood and consequences of severe reactor accidents in accordance with 10 CFR 50.109 [2]. The Risk R is defined as a function of scenarios Si that can go wrong, of how likely the scenario will happen (frequency fi), and of the consequence $\mathrm{Ci}$ of the scenario $\mathrm{Si}$ (Equation 1) [3].

$$
\mathrm{R}=\{\mathrm{Si}, \mathrm{fi}, \mathrm{Ci}\}
$$

The notion of risk includes both opportunities and threats. The basis of managing risk is to build multiple barriers between the threats that can lead to an adverse event of, for example, 
an operating a nuclear reactor. In the case of the Fukushima disaster of March 2011, the low frequency and high consequence event of the tsunami caused the removal of the diesel generators that provided the emergency power to circulate the water to cool the fuel rods in the reactor and in the cooling pools. Consequently, water and steam reacted rapidly with the zirconium material of the fuel cladding above $400^{\circ} \mathrm{C}$ producing enormous amounts of heat and hydrogen (Equation 2 ) that were vehicles for the release of some radioactivity into the environment.

$$
\mathrm{Zr}+2 \mathrm{H} 2 \mathrm{O}=\mathrm{ZrO} 2+\mathrm{H} 2+\text { Heat }
$$

Once the zirconium metal cladding was consumed by steam, the radioactive fuel is released inside the second barrier, the thick-walled steel reactor pressure vessel. That is, the effect of the tsunami in Fukushima was to destroy the first barrier or the metallic zirconium cladding containing the radioactive elements. To minimize the risk of failure of the operating plant, a stronger first barrier should be constructed between the fuel and the second barrier.

\section{RISK MANAGEMENT IN A NPP ENVIRONMENT}

Benefits from risk management in a nuclear power plant do not only include safety scenarios but also production (operational or engineering) and economics (financial) scenarios [4] (Figure 1). Each one of these risk disciplines will incorporate their own frequencies and consequences. Another discipline or scenario that can be added is the strategic one, which covers things like type of government in the country, nationalization or expropriations, public perception, regulatory and legal framework, etc. (represented as a larger square in Figure 1). It is important to identify all the consequences of an event (e.g. tsunami) to be able to minimize adversarial outcomes and to maximize public response and commercial gains in a cost-efficient manner [4]. The risk management framework is an iterative process in which first the possible risks are identified (together with potential consequences and relative impact of each consequence), then the techniques to manage the risk are identified (e.g. risk reduction or risk transfer), and finally the chosen strategies or techniques are implemented. This process is followed by monitoring and feedback to determine the effectiveness of the solutions and, if necessary, repeat the process with other improved measures. For example, risk reduction can be accomplished by engineering changes, organizational changes, staff training, etc. and risk transfer can be implemented by contracts with suppliers, insurance, regulation, etc.

Following the example from the Fukushima incident, one way of reducing risk in plant operation would be the engineering replacement of zirconium alloys from the nuclear fuel of the power plant with $\mathrm{FeCrAl}$ alloys. This is an obvious technical change that would greatly reduce the consequence of the explosion that considerably affected the public perception of safe operation of nuclear power plants. That is, the use of $\mathrm{FeCrAl}$ alloys can only produce opportunities to reduce the engineering risk identified in Figure 1. The FeCrAl alloy is the first barrier between the radioactive elements and the biosphere surrounding the NPP. By improving on the performance of the first barrier (cladding of the fuel), the consequence of combustible hydrogen explosion or release of radioactive elements outside the NPP is greatly minimized.

\section{ACCIDENT TOLERANT FUELS}

The US Department of Energy is working with the nuclear fuel vendors such as General Electric to develop an accident tolerant fuel that would be resistant to loss of coolant events such 
as the one in Fukushima in March 2011 [5,6]. A fuel may be defined as having enhanced accident tolerance if, in comparison with the current UO2-zirconium alloy system, it can tolerate loss of active light water cooling in the reactor core for a considerably longer time while maintaining or improving fuel performance during normal operations and operational transients, as well as in design basis and beyond design-basis events. The enhanced fuel material should have

- Improved reaction kinetics with steam;

- $\quad$ Slower hydrogen production rate;

- Improved cladding and fuel properties;

- $\quad$ Enhanced retention of fission products.

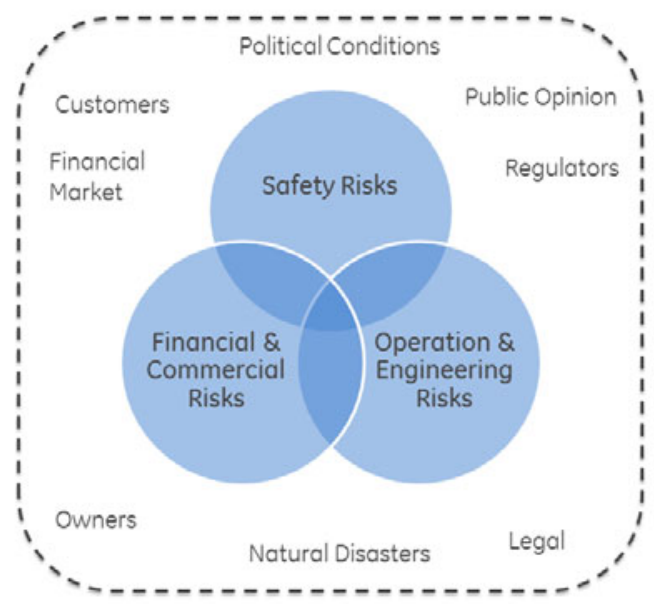

Figure 1. Risk management environment model for a nuclear power plant operator. The aim of the GE-ORNL team is to minimize engineering risks by using FeCrAl cladding.

The DOE provided a five-step guideline or metrics to assess the behavior of the ATF concept (Figure 2) [7]. That is, the concept for accident tolerant fuel rods must be able to perform as well as the current system under normal operation conditions in the order of 300$400^{\circ} \mathrm{C}$ cladding temperature (Step 1). This includes low corrosion rates in both boiling water reactors (BWR) and pressurized water reactor (PWR) environments, no environmental assisted cracking, no shadow corrosion, no hydriding that will render the rod brittle, no fretting or debris damage, etc. (Step 1). Also in Step 1, it needs to be demonstrated that the new fuel will be compatible with the thermal and hydraulic flow inside of the reactor. Step 2 requires that the ATF fuel rod would be better than the current zirconium - uranium dioxide system under design basis accidents including the temperature range between $400^{\circ} \mathrm{C}$ to $1200^{\circ} \mathrm{C}$ of the cladding temperature in contact with the coolant. Step 3 requires that under severe accident conditions ( $T$ $>1200^{\circ} \mathrm{C}$ ), the cladding would be superior to the current system, for example by tolerating reaction with steam to produce lower amounts of heat and explosive hydrogen gas [8]. Step 4 requires that the new ATF fuel rod can be manufactured easily using economical standard 
procedures such as tube fabrication and hermetical welding or sealing. Moreover, Step 4 covers the changes that are required in the regulators or licensing specifications that would allow for the new ATF rod to be deployed into a commercial light water reactor. Step 5 is concerned about the condition of the fuel rods after their useful life in the reactor, if the bundles can be safely and integrally removed from the reactor to be securely stored in cooling pools for a period of 5 years or more, and how the rods will perform under dry cask storage for periods in the order of 100 years.

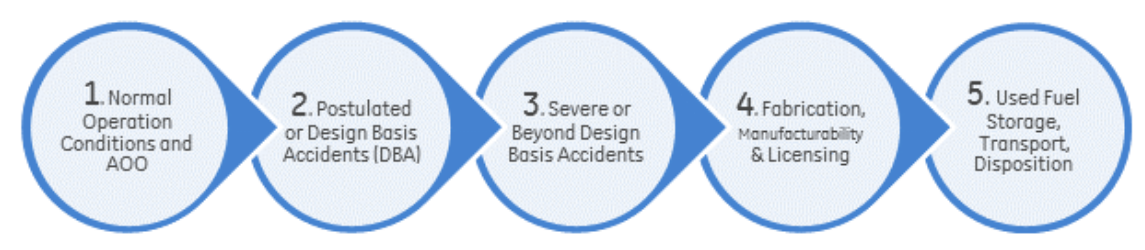

Figure 2. Five metric Areas Provided by DOE to Evaluate ATF [7].

The objective of the GE project is to develop a FeCrAl fuel cladding for current design light water power reactors. The idea of using $\mathrm{FeCrAl}$ alloys as cladding for current $\mathrm{UO} 2$ fuel is also supported by Oak Ridge National Laboratory (ORNL). The main reasons for the election of the ferritic $\mathrm{FeCrAl}$ alloy system was their remarkable resistance to attack by steam above $1200^{\circ} \mathrm{C}$ and their inherent resistance to stress corrosion cracking in $\sim 300^{\circ} \mathrm{C}$ water. The $\mathrm{FeCrAl}$ cladding concept is a near term solution for providing enhanced safety to light water reactors. FeCrAl has superior oxidation resistance in the event of a severe accident. FeCrAl has excellent environmental resistance characteristics under normal operation both for boiling and pressurized water reactors (BWR \& PWR) coolants. The use of FeCrAl would eliminate common/current fuel failure mechanisms such as fretting and shadow corrosion. There is no change in fuel type since it utilizes the current UO2 fuel. The current FeCrAl alloy candidate is APMT, but optimization alloy composition and fabrication studies continue at ORNL. ORNL and GE have been conducting research in the five areas listed in Figure 2 since 2012. The aim of this manuscript is to describe the maturity of the concept and the overall feasibility on the use of ferritic FeCrAl alloys as cladding for nuclear fuel in commercial light water reactors. GE and ORNL are following a methodical approach to evaluate metrics or performance attributes outlined by Bragg Sitton et al. [7].

It is noted that austenitic stainless steel (SS) materials were used for fuel rod cladding in the past both for US commercial plants and overseas NPP [9]. Preliminary studies on FeCrAl alloy materials indicate sufficient strength and ductility to perform acceptably as cladding alloy, like past use of austenitic SS cladding. FeCrAl alloys also do not contain nickel, which is a more expensive and higher neutron absorption element than $\mathrm{Fe}, \mathrm{Cr}$ or $\mathrm{Al}$. However, compared to experience with austenitic SS cladding, extensive crack propagation studies show that ferritic $\mathrm{FeCrAl}$ proved to be several orders of magnitude more resistance to environmentally-assisted cracking than modern type $304 \mathrm{SS}$ [6]. Because of its ferritic or bcc structure, FeCrAl alloys are also more resistant to irradiation degradation than prior versions of austenitic SS cladding 
materials. Proton irradiation studies performed at the U. of Michigan showed that $\mathrm{FeCrAl}$ materials may be resistant to proton irradiation induced cracking providing additional confirmation of the potential acceptability of FeCrAl materials for fuel rod cladding [10]. Although there may be nominal changes in fuel rod geometry (e.g. clad outer diameter -OD- and thickness) for lead rod assembly designs and in fuel assembly designs (e.g. fuel channels design) to accommodate differences in material performance in future fuel designs, such changes are expected to be incremental to existing fuel rod and assembly designs, significantly leveraging the knowledge base for current fuel designs for the new concept. Simulation studies performed at Brookhaven National Laboratory showed that there is little or no impact on the thermalhydraulic properties of the system by using a fuel rod clad with a FeCrAl alloy [10]. It is expected that a $\mathrm{FeCrAl}$ alloy clad fuel rod can be designed with minimal thermal-hydraulic design changes. $\mathrm{FeCrAl}$ alloy cladding is completely compatible with the current coolant chemistries used in either BWR or PWR reactors, that is, significant coolant chemistry changes are not expected because of $\mathrm{FeCrAl}$ implementation. Extensive immersion studies with chemistries typically observed in both BWR and PWR reactors showed excellent corrosion resistance of the $\mathrm{FeCrAl}$ alloys both under hydrogen and oxygen atmospheres [11].

Electrochemical studies in high temperature water showed that FeCrAl has a behavior like traditional reactor alloys such as type 304 SS and nickel based alloy X-750. Electrochemical studies performed at GE Global Research showed that $\mathrm{FeCrAl}$ rods in contact with a separator grid of alloy X-750 would not experience galvanic corrosion under irradiation conditions [12], allowing utilization of current existing grid/spacer designs.

\section{FABRICATION, MANUFACTURABILITY, LICENSING}

The $\mathrm{FeCrAl} / \mathrm{UO}_{2}$ fuel rod is compatible with current large-scale production technology. Uranium dioxide (UO2) pellet fabrication would remain the same as in the current process. Currently, tube fabrication trials are being conducted to demonstrate that $\mathrm{FeCrAl}$ alloys can be produced as long, thin walled tubes for fuel rod assemblies. Although the cladding fabrication process is yet untested for large scale production, there does not appear to be a significant barrier for production quantities of the cladding. Preliminary studies demonstrated FeCrAl compatibility with existing welding, manufacturing, and quality practices used with current Zircaloy based rod assembly systems. The fabrication processes for the $\mathrm{FeCrAl} / \mathrm{UO}_{2}$ system will be very like current light water reactor (LWR) fuel fabrication processes (pilgering/extruding, heat treatments, welding, nondestructive evaluation (NDE) techniques, etc.) which are mature and well understood. No issues are anticipated complying with current nuclear industry quality and performance standards.

It is expected that the path to NRC licensing for a FeCrAl alloy fuel rod concept would be direct and achievable. It is understood that the NRC fuel licensing process for cladding is currently zirconium centric but this does not prevent adaption for a FeCrAl alloy. The regulatory requirements governing safety limits for the core are well understood and $\mathrm{FeCrAl} / \mathrm{UO}_{2}$ fuel systems, in general, perform equivalent to or better than a zirconium $/ \mathrm{UO}_{2}$ fuel system with respect to plant safety.

The licensing processes to be employed to support the insertion of lead fuel rods or lead fuel assemblies -LFR/LFAs- are in place and can be used to meet the ATF program objectives, with the caveat that a licensing exemption to 10CFR50.46 will be required. However, Global 
Nuclear Fuels (GNF) anticipates that the NRC will be supportive of this request based on experience with other lead fuel programs.

$\mathrm{FeCrAl} / \mathrm{UO}_{2}$ fuel rod systems will have minimal or no impact in the handling of the fuel, shipping requirements and/or plant operations. It is expected that standard analyses techniques applied to zirconium alloy systems may be used substituting FeCrAl-specific properties to demonstrate acceptable performance under shipping and handling conditions, although licensing for shipping of the LFR/LFAs will need to be completed as well as in-core licensing. This could likely, however, be done under a special letter authorization for limited shipments rather than a change to the license certificate.

\section{USED FUEL STORAGE, TRANSPORTATION, DISPOSITION}

Spent fuel bundles with FeCrAl cladding are expected to maintain their geometries and therefore should be easily removed from the reactor and transported first to cooling pools and later to dry cask storage [13]. Their mechanical strength and ductility should be satisfactory for the transportation and handling of used fuel rods and assemblies. There is confidence that fuel bundles will maintain their geometry and acceptable material conditions through operation and storage. It is anticipated no loss of mechanical properties for the FeCrAl fuel rods during $>100$ years of dry cask storage [13]. FeCrAl alloys perform as well as or superior to existing zirconium based alloy systems in terms of heat transfer and heat removal for spent fuel rods. There are no anticipated issues regarding the thermal behavior for fuel rod designs using FeCrAl alloy cladding. Due to their chromium content, the $\mathrm{FeCrAl}$ alloy will remain passive in cooling pools. $\mathrm{FeCrAl}$ does not react with hydrogen to produce hydrides that may render the cladding brittle. That is, hydrogen does not accumulate chemically into the $\mathrm{FeCrAl}$ cladding. FeCrNi alloys (e.g. type 304 SS) have been used in the past as cladding for commercial fuel and they are currently under decades' long safe storage in the US $[9,13]$. There are no anticipated issues with chemical attack of the cladding due to fission by-products. However, due to the maturing nature of the final $\mathrm{FeCrAl}$ composition, additional studies should be performed during future accident tolerant fuel programs to evaluate the behavior of fission products and the chemical interaction with the cladding. Currently GE-ORNL is participating in neutron irradiation studies at Idaho National Laboratory Advanced Test Reactor (ATR) of $\mathrm{UO}_{2}$ fuel clad with $\mathrm{FeCrAl}$ to determine the chemical interaction between the fuel and the cladding (Test ATF-1). In the year FY2018, ATF-2 testing will start where fuel clad with APMT and other FeCrAl alloys will be exposed to neutron irradiation in presence of PWR secondary type water to determine both the resistance of the cladding to pellet cladding interaction -PCI- from the inner diameter-ID- of the tube and resistance to PWR coolant from the OD. FeCrAl clad fuel rods may be conventionally reprocessed after the end of their useful life in the power reactor. No major differences exist from the current Zircaloy/ $\mathrm{UO}_{2}$ system.

\section{ISSUES TO BE RESOLVED}

One of the issues that need to be successfully resolved before full implementation of a FeCrAl alloy clad system relate to mitigation of increased parasitic neutron absorption of the FeCrAl compared to zirconium alloys $[5,6,14]$. As a direct material substitution, (assuming some reduction in cladding thickness consistent with preliminary mechanical performance and some increase in fuel pellet mass) application of FeCrAl alloy cladding will increase fuel cycle 
costs. It is estimated that such an impact may be in the order of $20 \%$. Additional design changes (such as the fuel channel), may be required to meet bundle design requirements, further impacting fuel cycle economics. However, potential mitigation strategies have been identified that may partially or fully offset these penalties. Such mitigation strategies include alternate materials (e.g. silicon carbide composite channel materials), higher allowable heat generation rates, as well as relaxation of regulatory requirements due to much improved fuel cladding performance under normal/off-normal, design basis and beyond design basis accident conditions, which in turn will result in improved economics of plant operation. A second issue that requires resolution is the potential to increase release of tritium into the coolant. One potential mitigation strategy, currently under investigation, is formation of an alumina layer (or other type of permeation barrier) in the ID and/or OD of the cladding [15]. A thin alumina layer in the ID of the cladding will significantly reduce the hydrogen permeation from the fuel to the coolant.

\section{CONCLUSIONS}

1) The General Electric (GE) accident tolerant fuel (ATF) design concept utilizes a FeCrAl alloy material such as APMT as fuel rod cladding in combination with uranium dioxide (UO2) fuel pellets, resulting in a fuel assembly that leverages the performance of existing/current LWR fuel assembly designs and infrastructure with improved accident tolerance.

2) The use of FeCrAl APMT will greatly reduce the risk of plant operation by putting a primary barrier better than Zircaloy between the radioactive elements in the fuel and the second barrier which is the reactor pressure vessel.

3) Under accident conditions, $\mathrm{FeCrAl}$ alloys are orders of magnitude more resistant to reaction with superheated steam than zirconium, generating less combustible hydrogen. FeCrAl alloys would keep their coolable geometry for longer time allowing for quenching measures after a loss of coolant accident.

4) On the less favorable side, the $\mathrm{FeCrAl}$ alloys are less transparent to neutrons than zirconium alloys, which impacts fuel cycle cost. The FeCrAl cladding may release more tritium to the coolant. Both adverse characteristics can be minimized or eliminated by design, fabrication and regulatory modifications.

5) A FeCrAl alloy fuel cladding is the simplest, most cost effective and expeditious way to implement an ATF fuel design that combines the high performance of current fuel with significant accident tolerance.

\section{ACKNOWLEDGMENTS}

The financial support of Kelly Fletcher and Steve Duclos of GE Global Research is gratefully acknowledged. This material is based upon work supported by the Department of Energy [National Nuclear Security Administration] under Award Number DE-NE0008221. This report was prepared as an account of work sponsored by an agency of the United States Government. Neither the United States Government nor any agency thereof, nor any of their employees makes any warranty, express or implied, or assumes any legal liability or responsibility for the accuracy, completeness, or usefulness of any information, apparatus, product, or process disclosed, or represents that its use would not infringe privately owned rights. Reference herein to any specific commercial product, process or service by trade name, trademark, manufacturer, or otherwise does not necessarily constitute or imply its endorsement, recommendation, or favoring by the United States Government or any agency thereof. The views 
and opinions of authors expressed herein do not necessarily state or reflect those of the United States Government or any agency thereof.

\section{REFERENCES}

1. R. B. Rebak, "Nuclear Application of Oxide Dispersion Strengthened and Nano-Featured Alloys: An Introduction, JOM, Vol. 66, No. 12, pp. 2424-2426 (2014)

2. US Nuclear Regulatory Commission, Fact Sheet on Nuclear Reactor Risk, http://www.nrc.gov/reading-rm/doc-collections/fact-sheets/reactor-risk.html

3. N. Sridhar, "Risk Assessment of Corrodible Systems-An Overview," Materials Performance, June 2011, p. 32.

4. IAEA, International Atomic Energy Agency, "Risk management: A tool for improving nuclear power plant performance," TECDOC-1209, Vienna, 2001

5. S. J. Zinkle, K. A. Terrani, J. C. Gehin, L. J. Ott, and L. L. Snead, "Accident tolerant fuels for LWRs: A perspective," Journal of Nuclear Materials, 448 (2014) 374-379

6. R. B. Rebak, "Alloy Selection for Accident Tolerant Fuel Cladding in Commercial Light Water Reactors," Metallurgical and Materials Transactions E, Vol. 2E, 197-207 (December 2015).

7. S. M. Bragg-Sitton, M. Todosow, R. Montgomery, C. R. Stanek, R. Montgomery, and W. J. Carmack, Metrics for the Technical Performance Evaluation of Light Water Reactor Accident Tolerant Fuel, Nuclear Technology, 195(2), p. 111-123, August 2016.

8. K. R. Robb, "Analysis of the FeCrAl Accident Tolerant Fuel Concept Benefits During BWR Station Blackout Accidents," Proc. of NURETH-16, Chicago, IL, USA, August 30September 4, 2015

9. $\quad$ EPRI, Electric Power Research Institute, Evaluation of Expected Behavior of LWR Stainless Steel-Clad Fuel in Long-Term Dry Storage, EPRI, Palo Alto, CA: 1996. TR-106440

10. R. B. Rebak, N. R. Brown, and K. A. Terrani, "Assessment of Advanced Steels as Accident Tolerant Fuel Cladding for Commercial Light Water Reactors," Paper 227, 17th International Conference on Environmental Degradation of Materials in Nuclear Power Systems - Water Reactors, August 9-12, 2015, Ottawa, Ontario, Canada (Canadian Nuclear Society, Toronto).

11. D. D. Ellis, and R. B. Rebak, "Passivation Characteristics of Ferritic Stainless Materials in Simulated Reactor Environments," Paper C2016-7452, Corrosion/2016 (NACE International, Houston, TX).

12. Y.-J. Kim, F. Wagenbaugh, T. B. Jurewicz, R. J. Blair, and R. B. Rebak, "Environmental Behavior of Light Water Reactor Accident Tolerant Candidate Cladding Materials under Design Conditions," Paper C2015-5817, Corrosion/2015 (NACE International, Houston, TX)

13. R. B. Rebak, and S. Huang, "Anticipated Improved Performance of Advanced Steel Cladding Under Long Term Dry Storage of Spent Fuel,” Paper No. PVP2015-45643, pp. V007T07A042; 7 pages, doi: 10.1115/PVP2015-45643 (ASME 2015)

14. N. M. George, K. Terrani, J. Powers, A. Worrall, and I. Maldonado, "Neutronic analysis of candidate accident-tolerant cladding concepts in pressurized water reactors," Annals of Nuclear Energy, 75 (2015) 703-712

15. R. B. Rebak and Y.-J. Kim, "Hydrogen Diffusion in FeCrAl Alloys for Light Water Reactors Cladding Applications" Paper PVP2016-63164, 2016 ASME PVP Conference, MF-7 Materials and Technologies for Nuclear Power Plants, 17-21 July 2016, Vancouver, BC. 